\title{
Major reduction in asthma morbidity and continued reduction in asthma mortality in New Zealand: what lessons have been learned?
}

\author{
Jeff Garrett, John Kolbe, Glenn Richards, Toby Whitlock, Harold Rea
}

The initial retrospective surveys performed in New Zealand ${ }^{1-4}$ in the early 1980 s to examine the possible causes of the epidemic of asthma deaths which began to occur in the late 1970 s proved useful in generating a number of hypotheses. These included: (1) an increase in the prevalence of asthma, ${ }^{56}(2)$ an increase in the severity of asthma, ${ }^{7}$ (3) changes in the provision of, and access to, primary health care,$^{8-10}(4)$ direct drug toxicity, due either to individual drugs or a combination of drugs, ${ }^{11}$ (5) management error by patient, relative or doctor during the fatal attack, ${ }^{312}$ and (6) other deficiencies in medical management. ${ }^{31213}$

The more recent literature relating to the New Zealand epidemic has included case control studies ${ }^{14-18}$ retrospective dynamic cohort studies, ${ }^{1920}$ and randomised clinical trials ${ }^{21}$ and has refocused interest back on inhaled $\beta$ agonists as the potential cause of the epidemic. However, a closer scrutiny of the trends in both asthma mortality and morbidity from the late 1970 s through to the early 1990 s suggests that there were likely to have been other factors which not only contributed to the epidemic, but also to the subsequent decline in asthma mortality and morbidity. These factors will be reviewed in this paper.

\section{Epidemiology in relation to the asthma epidemic in New Zealand \\ AN INCREASE IN PREVALENCE}

Whilst there is some evidence that the prevalence of asthma increased at the time of the mortality epidemic, ${ }^{6}$ it would not have been sufficient to have accounted for the threefold increase in deaths from asthma. Since diagnostic criteria for asthma had not been standardised or validated at the time, any subsequent changes in prevalence could have been due to a change in recognition or labelling by either doctor or patient as a result of the publicity surrounding asthma in New Zealand. Certainly, international studies using the same methods of defining asthma have found no difference in the prevalence of asthma in children between New Zealand, Australia, and Canada $^{22-24}$ in spite of the fact that there were 2-3 fold differences in both hospital admission and mortality rates from asthma between these countries. Furthermore, Pattemore et $a l^{25}$ could not find important ethnic differences in the prevalence of either asthma symptoms or levels of airway hyperresponsiveness in New Zealand to account for the 3-4 fold difference in admission rates and mortality rates between Europeans and Polynesians. Although airway hyperresponsiveness has been accepted as part of the criteria for a diagnosis of asthma in prevalence studies and is related to clinical asthma, it is not identical to it $(8-15 \%$ of children who have never wheezed will show airway hyperresponsiveness and as many as $30 \%$ with typical asthma will fail to show it on several occasions ${ }^{26}$ ) and therefore cannot reliably or precisely separate asthmatic from non-asthmatic subjects. In addition, airway hyperresponsiveness is more usually measured at one point in time in prevalence studies whilst questionnaires extract information on symptoms experienced over the preceding year or years. Even detailed history taking (on which the clinical diagnosis of asthma largely depends) lacks objectivity. There has been a tendency recently to accept the prescription of asthma medication as fulfilling a diagnosis of asthma. ${ }^{2728}$ However, asthma medications are often prescribed for an acute bronchitis which may also cause symptoms which are difficult to distinguish from those of asthma in a questionnaire survey. Until a clear internationally accepted definition for asthma was developed by Toelle $e t a l^{29}$ the wide variety of study methods made it difficult to be certain about the true prevalence of asthma and whether reported increases were real or apparent, both in New Zealand ${ }^{6}$ and elsewhere. ${ }^{3031}$ The recent finding by Peat $e t a l^{32}$ of a significant increase in airway hyperresponsiveness in two 8-10 year old populations during two different time periods (1982 and 1992) therefore remains the strongest argument for an increase in prevalence, although these results need to be reproduced in other studies, in other countries (and in older patients), and preferably in populations followed longitudinally.

\section{AN INCREASE IN SEVERITY}

Changes in mortality and morbidity rates may result from a change in either baseline asthma 


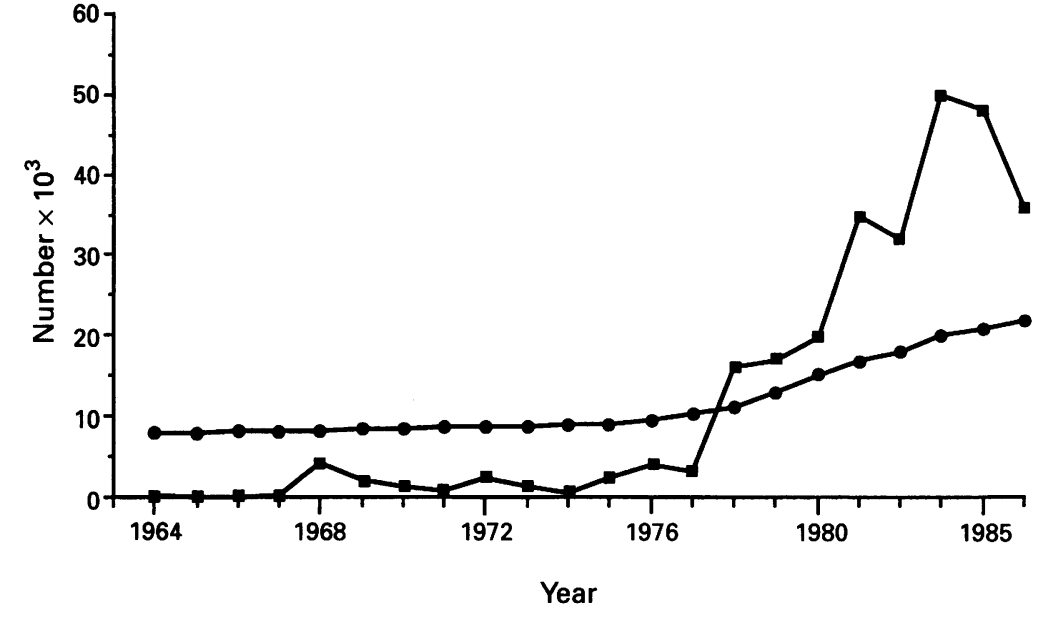

Figure 1 Unemployment $(\square)$ and invalid benefits ( - 10 ) in New Zealand 1964-85. Adapted from ref 35.

severity or frequency of acute severe attacks. However, many of the measures of morbidity may be influenced by confounding factors including diagnostic transfer, an increased tendency for individuals or families to seek consultation (particularly from hospital based medical care) when confronted with worsening asthma, a change in the emphasis from community to hospital based management of acute asthma, and changes in admission criteria. ${ }^{33}$ Although there were 2-3-fold differences in asthma mortality between New Zealand, Australia and Canada, cross-sectional studies in children using the same definitions of asthma severity and measurements of airway hyperresponsiveness have shown no differences between these countries. ${ }^{22}{ }^{23}$ Since a small increase in asthma severity may contribute to a modest increase in the absolute number of patients with severe asthma who would be at greater risk of hospital admission or mortality, ${ }^{734}$ the possibility of a small increase in severity

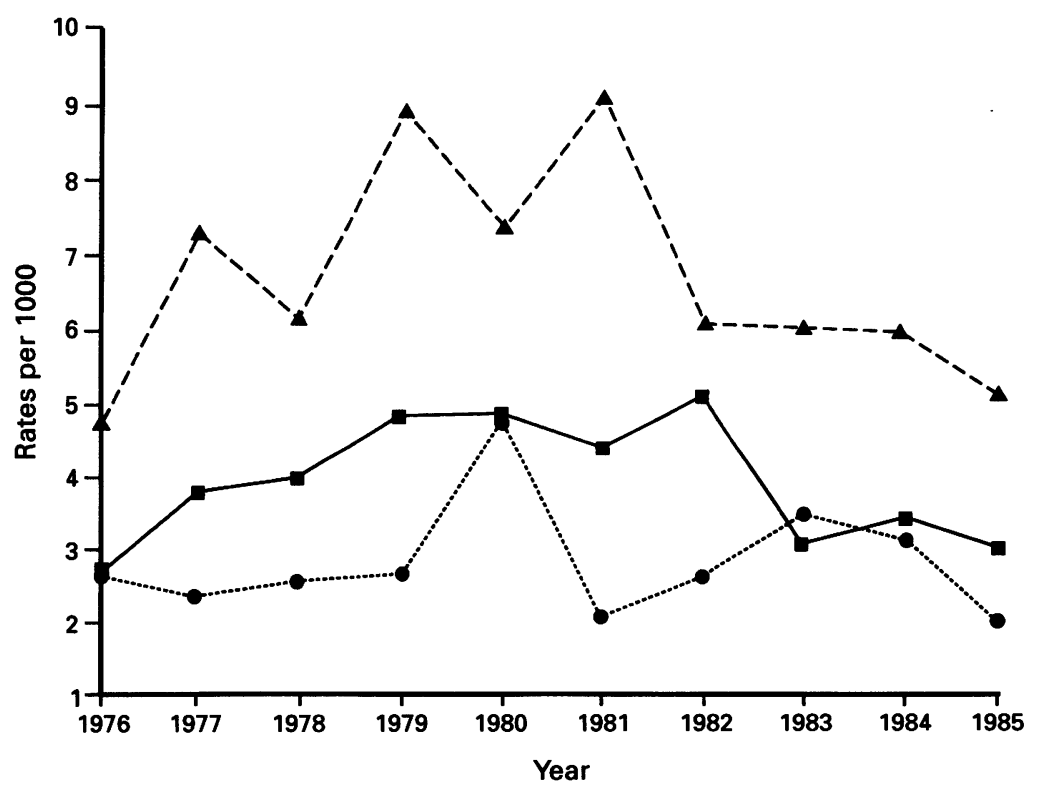

Figure 2 Asthma mortality rates (per 100000 ) by neighbourhood in New Zealand in patients aged under 60 years, $1976-85$. Low $(\mathbf{\Delta - \Lambda})=12.5 \%$ of areas of greatest need; middle $(-15 \%$ of areas of average need; high $(\cdots)=12.5 \%$ of areas of least need. ${ }^{37}$ Reprinted with permission from NZ Med $¥$. during the 1970 s cannot be completely discounted.

CHANGES IN PROVISION OF AND ACCESS TO HEALTH CARE

In 1941 New Zealand adopted a fully socialised form of health care in which medical treatment was made free to all. During the past 25 years, however, there have been substantial changes in the provision of, and access to, primary health care in New Zealand. A steady decline in the economy has led to an increase in the direct cost of primary health care to the individual. Further, there was a dramatic increase in unemployment in $1977^{35}$ (fig 1) which was temporally associated with a sudden increase in asthma admission and mortality rates. As Rea $e t \mathrm{al}^{14}$ have shown, psychosocial problems (of which recent unemployment was a component), when measured retrospectively from hospital records or relatives, were independently associated with an increased risk of death from asthma, $R R=3.5$ (95\% CI 1.04 to $13 \cdot 7)$ when patients dying of asthma were compared with hospital controls (and would have been expected to have been of greater significance if the control group had been made up from asthmatics in the community since psychosocial problems are likely to be associated with asthma morbidity ${ }^{36}$ as well as mortality). Therefore, although psychological and social factors are likely to be important, there have been few systematic data collected in New Zealand or internationally to evaluate the interrelationship between psychosocial and other risk factors for death.

At the beginning of the epidemic mortality rates were already twice as high in disadvantaged neighbourhoods as in middle class or advantaged areas in New Zealand. ${ }^{37}$ However, the subsequent increase in deaths occurred mainly in the middle and lower socioeconomic areas (fig 2), the increase in mortality rate in lower socioeconomic class areas being 2.3 times that of higher socioeconomic areas. A lack of accessibility to primary health care for financial, social, and cultural reasons, in association with poor organisation of after hours care, might explain why over $50 \%$ of patients who died from asthma had not sought medical help during their final attack, why there was an increased frequency of deaths and intensive care unit admissions on Sunday, ${ }^{38}$ and why discontinuity of medical care - an independent risk factor for death ${ }^{14}$ was twice as common in Polynesians as in Europeans. Such factors might also explain why Maoris and Pacific Islanders were three or four times more likely to die from asthma than Europeans, ${ }^{2}$ particularly when attempts to control the socioeconomic class may have underestimated the social disadvantage of Maoris and Pacific Islanders. ${ }^{39}$

We cannot determine whether the epidemic was as a direct result of increasing financial barriers to health care or whether patients living in middle class and disadvantaged areas were at increased risk of death as a result of, say, an increase in asthma severity or an increase in 


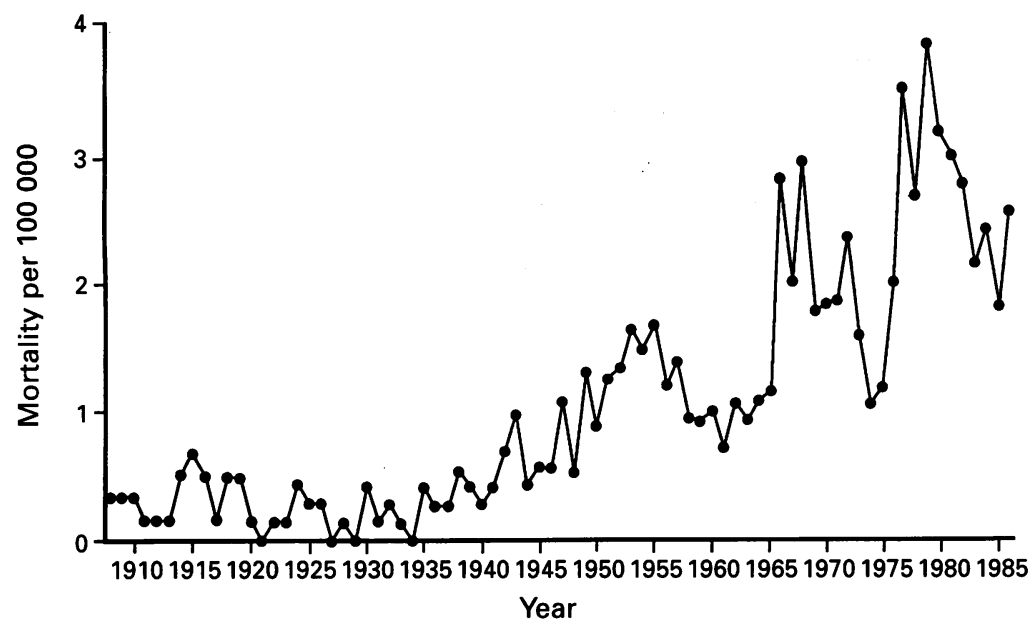

Figure 3 Asthma mortality (per 100 000) in non-Maoris aged 5-34 years in New Zealand, 1908-86. ${ }^{40}$ Reprinted with permission from Aust NZ Med $\mathcal{F}$.

psychosocial problems. However, it could be argued that social and economic changes and increasing barriers to primary health care would not have had such an immediate impact as to have caused the steep increase in asthma morbidity and mortality in 1976 . Nevertheless, such factors would have created an environment in which the release of new powerful bronchodilators may have contributed to a further delay in seeking appropriate medical care when patients were developing attacks of asthma. Further, although the focus of attention has been on the " 1976 epidemic", it is worth noting that asthma mortality rates have been increasing throughout the century, certainly since the $1950 \mathrm{~s}^{40}$ (fig 3), and may reflect changes in illness behaviour and a tendency towards increasing psychosocial problems over time. Whilst no research has been performed prospectively to gauge the effect of social and economic factors in relation to other risk factors for asthma death or near death, their potential importance nevertheless needs to be acknowledged.

\section{DRUG TOXICITY}

Early ecological association studies showed an increase in all asthma medicines, but particularly in sales of $\beta$ agonists and oral theophylline,${ }^{11}$ in association with increasing asthma

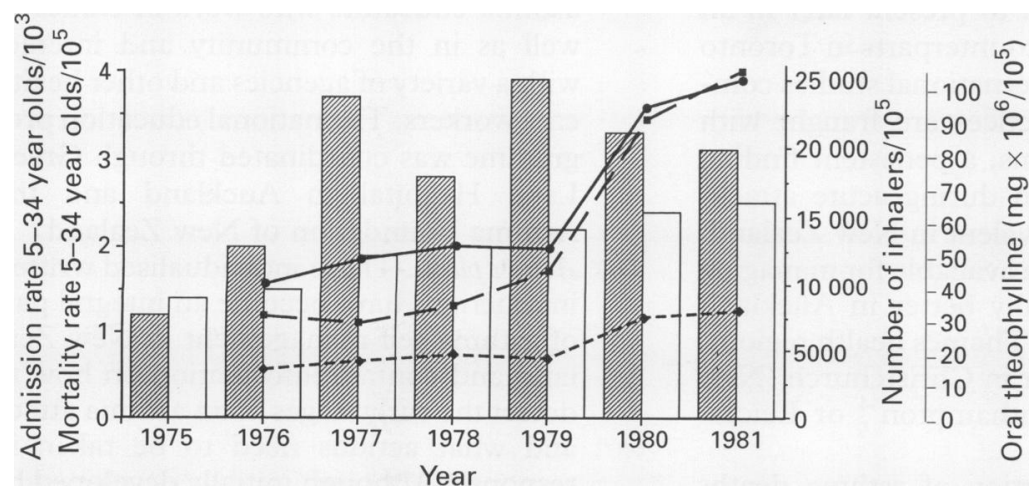

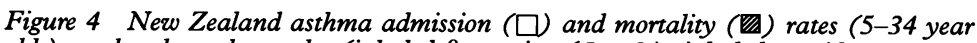
olds), and asthma drug sales (inhaled $\beta$ agonists (-), inhaled steroids $(\diamond-\bullet)$, oral theophyllines (- mortality and morbidity during the late 1970 s (fig 4)..$^{4142}$ Concern was expressed at the time as to why the increase in mortality had occurred in New Zealand despite this large increase in drug sales. ${ }^{41}$ The possibility of direct toxicity of asthma drugs, singly or in combination, was suggested, and since the rise in mortality and admission rates preceded the rise in drug sales, it was considered that the increase in sales of asthma drugs had occurred in response to a perceived increase in asthma morbidity, though acknowledging that the temporal sequence was examined nationally rather than on an individual basis. ${ }^{43}$ The rate of increase in sales of asthma medicines occurred at a rate which was 2-3 times that of Australia and the UK, ${ }^{41}$ though this may have resulted from lack of financial disincentive to their acquisition in New Zealand in the 1970s and early 1980s compared with prescription charges encountered by asthmatic subjects in Australia or the UK.

Fragmented primary health care combined with the use of powerful new bronchodilators may have been a particularly hazardous combination. In a recent study by Rea et $a l^{44}$ the number of visits to general practitioners in a cross-sectional survey of 381 asthmatic school children was positively associated with good self management skills. Patients living in disadvantaged areas in New Zealand are known to use multiple primary health care facilities (possibly to escape payment), leading to poor quality and fragmented medical care. Clinical assessment would have been limited by a lack of knowledge of the individual patient's condition and follow up would have been adversely affected by the same increasing financial barriers. This is further illustrated in a study of asthma undertaken in South Auckland, an area recognised as having high medical and social needs. ${ }^{10}$ Patients received good quality care for their acute attack in the hospital emergency department with a relapse rate of only $5.3 \%$ at one week ${ }^{10}$ (better than that described in most other published studies of emergency department $\operatorname{care}^{45}$ ), but the relapse rate at one month was $21.7 \%$ and was thought to reflect a low rate of prescription of inhaled corticosteroids subsequent to the asthma attack and a lack of ongoing medical care within the community.

The working party established by the Committee on Safety of Medicines in the $\mathrm{UK}^{46}$ reviewed the three New Zealand case-control studies published since 1989 which had shown that patients who died from asthma were more likely to have been prescribed inhaled fenoterol. ${ }^{15-17}$ It concluded that "...the potential for confounding by disease severity precluded confirmation of a causal association between fenoterol and asthma deaths". Whilst the initial analysis of a study performed in Saskatchewan to evaluate the association between the use of $\beta$ agonists and death and near death found that the effect estimate increased for fenoterol after adjustment for asthma severity, ${ }^{47}$ when a more appropriate statistical model was used this finding was corrected. ${ }^{48}$

The inability of Spitzer $e t a l^{47}$ to "adequately 
correct for asthma severity" prevented the Committee on Safety of Medicines from confirming the hypothesis that increasing use of inhaled $\beta$ agonists was causally associated with asthma mortality. ${ }^{46}$ Appropriately, however, Spitzer et al pointed out that regardless of whether $\beta$ agonists are directly responsible for adverse effects or are simply a marker of more severe disease, heavy use of these agents should alert clinicians to the need to re-evaluate a patient's condition. In the New Zealand context, increasing financial barriers to primary health care may have contributed to patients not seeking appropriate advice when their asthma was becoming more troublesome and their $\beta$ agonist use excessive. In a recent prospective study by Kolbe et al (unpublished data) to investigate risk factors for severe life threatening attacks of asthma, $62 \%$ of patients admitted to hospital had had symptoms of worsening asthma for more than 24 hours (only $7 \%$ had attacks of less than six hours) and $40 \%$ stated they had used more than 20 puffs of inhaled $\beta$ agonist in the 24 hours before presentation. Windom et al ${ }^{49}$ have also described a similar pattern of use: of 101 adult asthmatic patients admitted consecutively to a large urban hospital in New Zealand $40 \%$ stated they had used more than 30 doses of inhaled $\beta$ agonist (and $76 \%$ of the 17 patients owning nebulisers had used their nebulisers more than five times) in the 24 hours preceding admission. This practice is in contrast with internationally recommended usage of no more than a maximum of 15 doses of inhaled $\beta$ agonist per day. ${ }^{5051}$

\section{DEFICIENCIES IN MEDICAL MANAGEMENT}

Comparative studies using hospital case notes and information from general practitioners showed that the duration of illness before admission was greater in Auckland than in the South-West Thames health region in the UK. ${ }^{52}$ Furthermore, the proportion of asthmatic patients who had had symptoms of deteriorating asthma for more than 24 hours before attendance at the emergency department may be higher in New Zealand $(48 \%)^{7}$ than appears to be the case in Australia (25\%) (A Bauman, personal communication). In another comparative study of use of emergency departments asthmatic subjects in Auckland ${ }^{45}$ were found to use the emergency department in greater numbers and to present later in an acute attack than their counterparts in Toronto (Canada). Although international studies comparing health care practices are fraught with methodological problems, a persistent finding is that late presentation during acute attacks appears to be more prevalent in New Zealand, whilst the quality of care available for managing acute asthma is generally better in Auckland than in the South-West Thames health region ${ }^{52}$ or Toronto, ${ }^{45}$ and better in Christchurch (New Zealand) $)^{53}$ than in Southampton ${ }^{54}$ or Leicester. $^{55}$

Although the proportion of asthma deaths considered preventable was no higher than in the $U K,{ }^{56}$ delays in seeking medical care were found more consistently in New Zealand where
$50 \%$ had not called for medical help until they were in extremis. The consistent theme throughout all of these studies was the underutilisation of primary health care, particularly after hours where organisation barriers to community care existed along with financial barriers, presumably as a result of an increase in cost against a background of social and economic decline in the 1970s.

\section{Implementation of changes to asthma management in New Zealand}

Despite the problem of increasing financial barriers to primary health care and the subsequent introduction of part charges on prescriptions, a number of initiatives were introduced during the 1980 s to help to reduce mortality from asthma:

(1) Development of an asthma task force. In response to the "epidemic" of asthma deaths the New Zealand Medical Research Council set up an asthma task force. Although studies performed did not identify a single cause for the epidemic, asthma management policies were implemented to help to correct the multiple deficiences identified.

(2) National education campaigns. These were directed separately at the lay public, patients, and medical community. As a result the community's awareness of asthma was heightened, specifically its potential severity and life threatening nature.

(3) Educational material. A variety of education materials including a series of pamphlets and a video illustrating various asthma scenarios were produced by the Asthma Foundation of New Zealand and distributed nationally through asthma societies, hospitals, outpatient clinics, and general practitioners.

(4) A multidisciplinary approach to long term care was developed harnessing the skills and expertise of doctors, nurses, physiotherapists, clinical psychologists, social workers, community health workers, and those working in asthma societies.

(5) Specialist asthma "nurse" educators. A programme was developed for the training, certification, and ongoing education of asthma educators who work in clinics as well as in the community and interact with a variety of agencies and other health care workers. The national education programme was coordinated through Green Lane Hospital in Auckland and the Asthma Foundation of New Zealand.

(6) Action plans. These individualised written instructions have become an integral part of asthma self management in New Zealand and contain information on how to detect the early stages of an asthma attack and what actions need to be taken in response. Although initially developed by individual physicians or groups, the action plan has recently been standardised using a colour coded system produced by the 


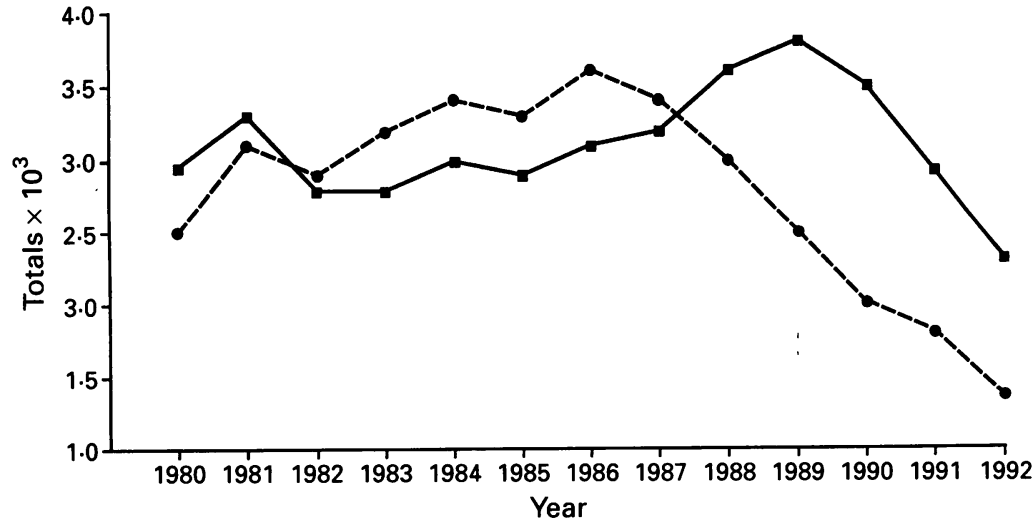

Figure 5 First admissions ( $\square-2$ ) and readmissions (---O) per calendar year for asthma in 5-54 year old New Zealanders (1980-92).

Asthma Foundation of New Zealand ${ }^{57}$ for both adults and children.

(7) Peak flow meters. These have been available free to general practitioners on wholesale prescription order since 1986 and are now distributed through the Asthma Foundation in association with other educational material. Cross sectional studies of asthmatics show that $40-60 \%$ now own a peak flow meter. ${ }^{5758}$ In the past three years sufficient meters have been distributed to supply one to each of the estimated 200000 asthmatic patients in New Zealand. ${ }^{59}$

(8) Promotion directed at the public of the need for earlier access to acute medical services for the treatment of acute asthma. A cross sectional study comparing the severity of asthma in patients attending an emergency department in 1979 with that in 1985 showed that mean peak flow measurements on presentation were significantly higher in $1985,{ }^{10}$ suggesting that patients were beginning to attend the emergency department earlier in an attack.

(9) Better organisation of after hours care, including an improved ambulance service responding to calls for acute asthma in a similar fashion to those for suspected acute myocardial infarction. Ambulance officers were trained to administer nebulised salbutamol and adrenaline sub-

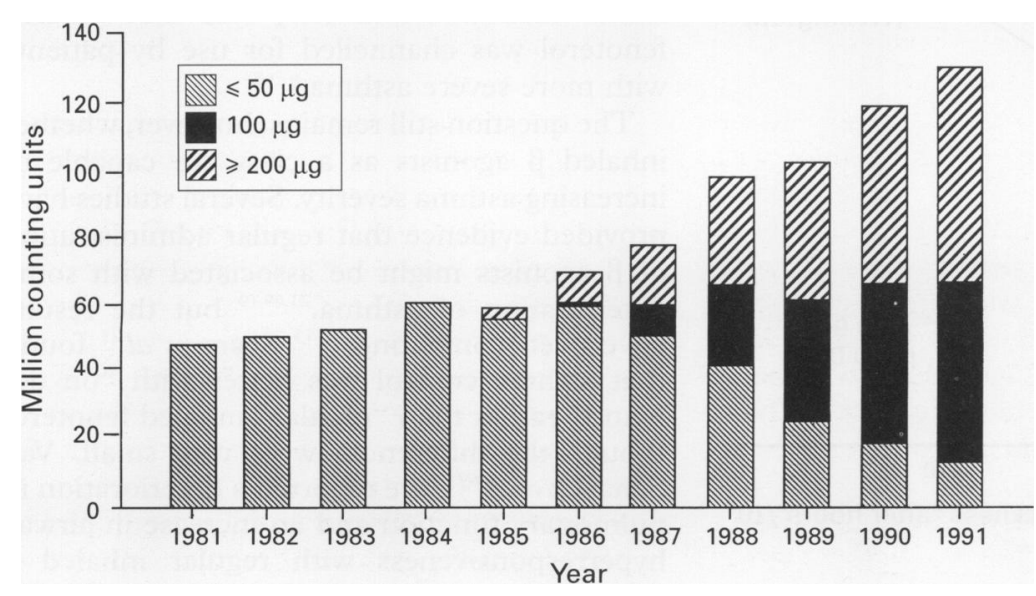

Figure 6 New Zealand inhaled steroid sales by dose 1981-91. cutaneously (or intravenously if the patient was not responding to other measurements). In 1990 there were 4359 call outs nationally (incidence $1 \cdot 25$ per 1000 ) for assistance with management of acute asthma. The average response time from call out to arrival was only nine minutes and $78 \%$ were transferred to hospital (personal communication). The earlier and more appropriate treatment of acute attacks in the community is likely to have contributed to a reduction in mortality and, initially, to an increase in hospital admissions including those to intensive care units. ${ }^{38}$

(10) The development of free hospital-based specialist asthma clinics which targeted patients considered to be at greatest risk of mortality or further hospital admission. Although such clinics have not been evaluated in a randomised prospective trial, two separate studies have shown reduced asthma admissions ${ }^{6061}$ and mortality ${ }^{60}$ in the year subsequent to referral for those who attended when compared with those who did not attend. Readmissions for asthma began to fall in 1986 (fig 5) 3-4 years before a fall in first admissions, suggesting that the strategy of targeting "at risk" patients by referring them to hospital based asthma clinics was having the desired effect. Such "high risk" patients would also have been channelled "higher dose" inhaled steroids which became available for "specialist only" use in 1985.

(11) Increased use of regular inhaled corticosteroids and of oral corticosteroids to treat acute exacerbations. The substantial increase in the use of medium and high dose inhaled steroids nationally (fig 6) and or oral corticosteroids in treating acute attacks of asthma in the emergency department ${ }^{10}$ between 1979 and 1985 suggest that these management strategies have been effective.

\section{Downward trends in asthma mortality and morbidity}

In New Zealand a progressive reduction in mortality from 4.1 per 100000 to 1.9 per 100000 in 5-34 year olds between 1981 and 1989 occurred. However, hospital admission rates, which had begun to increase at the same time as mortality rates, remained elevated throughout the 1980s (fig 7). Furthermore, the marked increase in intensive care unit (ICU) admissions in Auckland (without a change in admission criteria for the $\mathrm{ICU}^{38}$ ), and the continuing increase in first admissions nationally (fig 5), suggested that the number of severe attacks occurring in the community was rising at the time when mortality was declining.

We believe that the reduction in mortality during the $1980 \mathrm{~s}$ is best explained by earlier intervention in the management of severe attacks with an increase in the appropriate utilisation of hospital based care. This was not unexpected as the initiatives introduced at the 


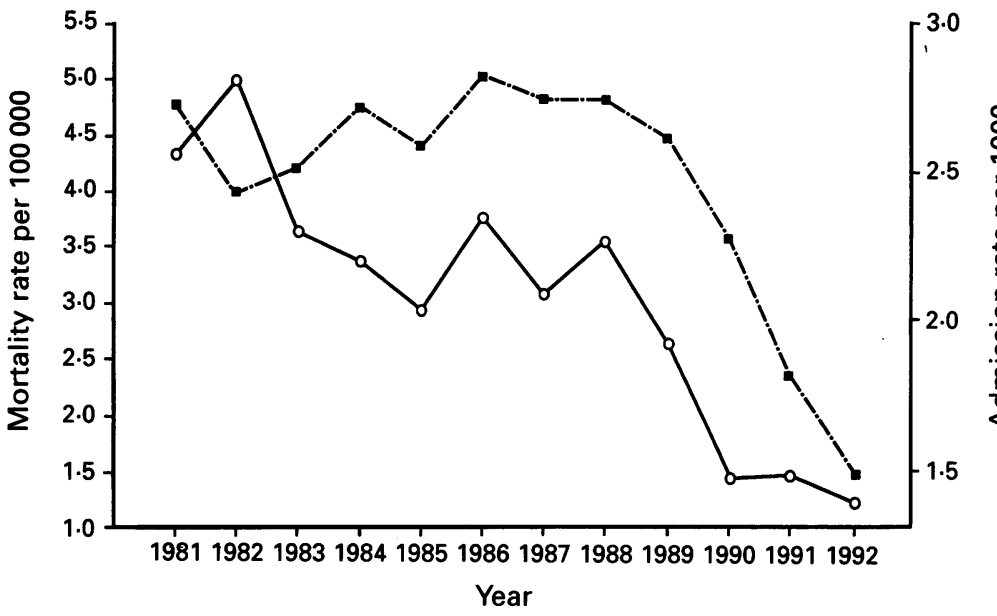

Figure 7 Asthma mortality rates (per 100000) ( $\mathrm{O}-\mathrm{O}$ ) and admission rates (per 1000) ( $\square-\cdot-(-)$ in 5-54 year olds in New Zealand 1981-92.

beginning of the 1980 s were mainly aimed at reducing the delays in treating acute attacks. Improvements in long term care would have been expected to have taken longer to implement than improved treatment of acute attacks, and therefore indices or morbidity such as hospital admissions, emergency department use, and use of ambulance services would have taken longer to decline.

In relation to hospital admissions there is a complex relation between disease severity, illness behaviour, and utilisation of health care services which would be difficult to evaluate even with a prospective study. A recent study by Strachan et $a l^{62}$ concluded that in the UK the rise in hospital admission rates for childhood asthma was more likely to reflect trends in provision and utilisation of health services, particularly after hours, ${ }^{63}$ than major changes in morbidity, and we have made similar observations in New Zealand. ${ }^{919}$ It would have been expected that this trend would have been more striking in New Zealand where there was no charge for hospital based care, as opposed to primary health care, and at a time when we were promoting more frequent and earlier use of hospital based services for the management of asthma. Indeed, most adult hospital admissions for asthma follow self referral. ${ }^{10}$ The

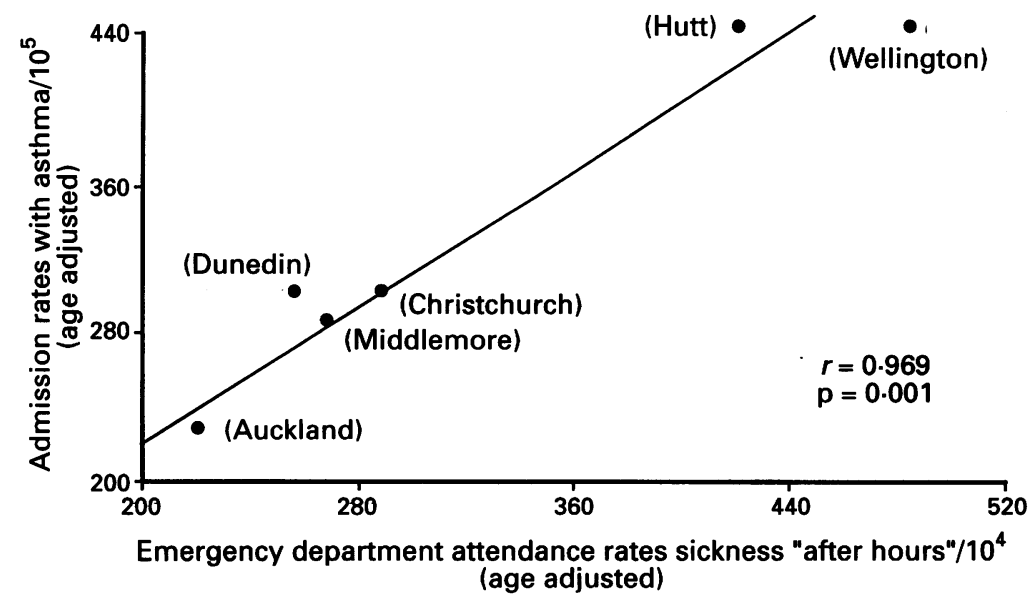

Figure 8 Age standardised asthma admission rates and emergency department "after hours" attendance rates for sickness in New Zealand's four main centres in 1981. higher emergency department use and admission rate for asthma by Maoris and Pacific Islanders was more likely to be due to differences in availability of community based medical care, a lack of self management skills and preventive medications, and socioeconomic factors than to differences in baseline severity. ${ }^{9}$ For the major hospitals serving New Zealand's four main centres there was a correlation between the attendance at emergency departments after hours for any sickness (age standardised) and hospital admissions with asthma (age standardised) $(R=0.96, \mathrm{p}=0.001)$ (fig $8)$. The sociodemographic characteristics of patients attending the emergency department with sickness are identical to those of asthmatic patients. ${ }^{864}$ Differences in admission rates between hospitals in New Zealand are therefore likely to reflect the sociodemographic characteristics of the surrounding community and the organisation of after hours medical care. If such characteristics can explain twofold differences in admission rates within New Zealand, then the same reasoning may explain the twofold differences between admission rates in New Zealand and other western countries ${ }^{65}$ without the need to evoke differences in either prevalence or severity of asthma.

More recently the situation has changed further. Since 1990 there has been a dramatic fall in all measures of asthma morbidity: a $70 \%$ reduction in ICU admissions in Auckland (New Zealand's largest city), a 34\% reduction in hospital admissions and use of acute ambulance services nationally, and a $25 \%$ reduction in emergency department use in Auckland. The asthma mortality rate, which had continued to fall gradually through the 1980 s, has taken a further steep reduction in 1990. These recent changes suggest that there has now been a reduction in the baseline severity of asthma or in the frequency of severe attacks. Recent publications have suggested that this recent reduction in mortality is due to the withdrawal of inhaled fenoterol. ${ }^{4066}$ Inhaled fenoterol was effectively withdrawn from the market in late 1989 as a result of the casecontrol studies ${ }^{15-17}$ which had shown an association between prescribed inhaled fenoterol and mortality. Subsequent studies performed by ourselves ${ }^{1920}$ and others ${ }^{48}$ suggest that the association was due to confounding by severity rather than a causal one, and that inhaled fenoterol was channelled for use by patients with more severe asthma. ${ }^{6768}$

The question still remains, however, whether inhaled $\beta$ agonists as a class are capable of increasing asthma severity. Several studies have provided evidence that regular administration of $\beta$ agonists might be associated with some deterioration of asthma, ${ }^{216970}$ but the results have been conflicting. ${ }^{71-73}$ Sears et al $^{21}$ found that asthma control was better with "on demand" rather than "regular" inhaled fenoterol though the differences were very small. Van Schayck et $a l^{69}$ have reported a deterioration in pulmonary function and an increase in airway hyperresponsiveness with regular inhaled $\beta$ agonist use, though the changes were not associated with worsening asthma symptoms. If 
the conclusions of these studies are correct, then regular and high dose use of inhaled $\beta$ agonists including fenoterol may have led to a worsening of chronic severity of asthma and thereby have increased the risk not only of death, but also hospital admission. If this were the case then indices of chronic severity would be intermediate in the causal pathway. Although indices of chronic severity employed in the Wellington group's case-control studies ${ }^{15-17}$ did not consistently reduce the relative risk for mortality in patients prescribed inhaled fenoterol, as should have occurred if such a mechanism existed, this may have been due to control selection bias ${ }^{74}$ in the first two studies $^{1516}$ and to the inadequate measures of severity which were available to the researchers.

Even if fenoterol was accepted as a risk factor for asthma death (and also hospital admission), it is clearly not the only reason for the New Zealand epidemic. Using calculations derived from the Wellington research group study ${ }^{17}$ and those supplied by IMS (NZ) Limited, a maximum of $45 \%$ of asthma deaths and $25 \%$ of asthma admissions could have been attributed to inhaled fenoterol. ${ }^{75}$ Since the restriction of inhaled fenoterol there has been a greater $(59 \%)$ reduction in mortality than would have been predicted (38\%) if the epidemic was solely attributable to inhaled fenoterol. ${ }^{75}$ Asthma mortality was already declining in New Zealand before 1989, and mortality rates in 1989 and 1990 fell within the $95 \%$ confidence intervals predicted by this trend. ${ }^{76}$ Furthermore, the steep rise in asthma mortality after the introduction of inhaled fenoterol in 1976 would not have been predicted by applying the crude relative risk of 2.0 for fenoterol during $1977-81 .{ }^{77}$ Using this analysis the rate of asthma deaths before 1976 would have increased from $1 \cdot 5 / 10^{5}$ to around $2 \cdot 0 / 10^{5}$, not $4 \cdot 1 / 10^{5}$ as was observed in $1979 .{ }^{77}$ In our studies $^{1920}$ we used a methodology which was better able to deal with confounding (retrospective dynamic cohort) than the Wellington studies ${ }^{15-18}$ and were able to define better quality indices of severity. Once we were able to

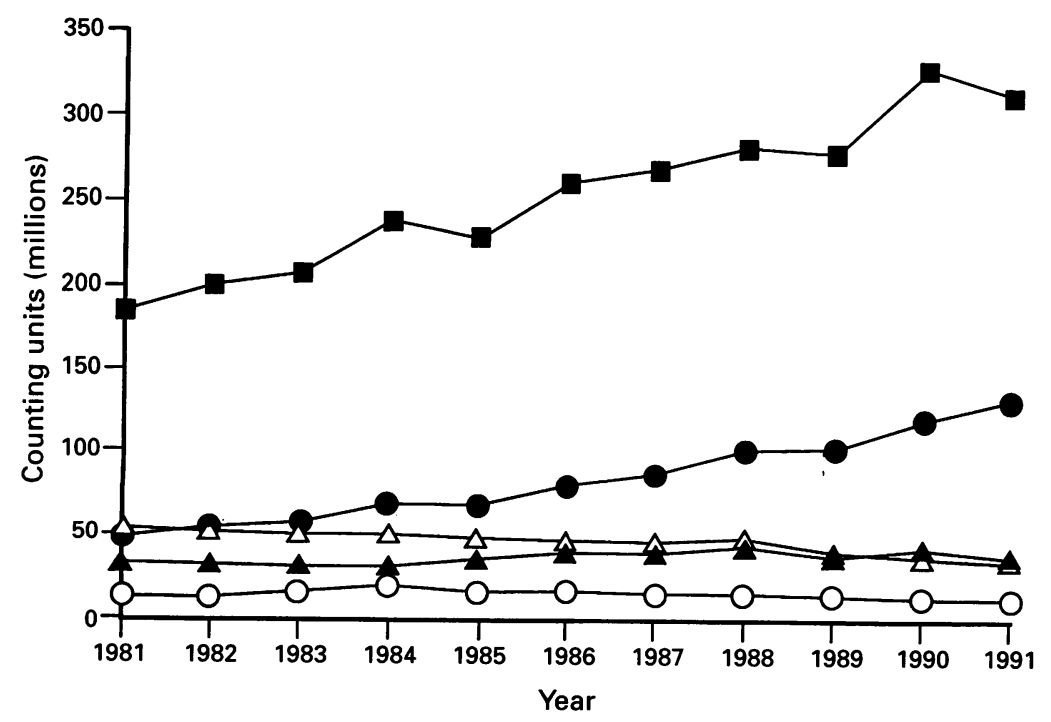

Figure 9 Drug sales in New Zealand 1981-91: inhaled $\beta$ agonists ( $\square$ ), oral $\beta$ agonists $(\triangle)$, oral theophyllines $(\triangle)$, inhaled cromoglycate $(\mathrm{O})$, and inhaled steroids ( $\mathrm{O})$. control for severity the crude rate ratio of $2 \cdot 0$ associated with risk of death or near death in patients taking fenoterol, when compared with salbutamol as used in the previous studies, ${ }^{15-18}$ reduced to $1 \cdot 1(95 \% \mathrm{CI} 0 \cdot 57$ to $2 \cdot 22){ }^{19}$

Little has been made of the fact that oral theophylline was associated with an increased risk of mortality in both the Saskatchewan, ${ }^{47}$ $\mathrm{RR}=3.3(95 \%$ CI 1.3 to $8 \cdot 8)$ and the most recent of the Wellington group's studies, ${ }^{17}$ $\mathrm{RR}=1.85$ (95\% CI 1.09 to 3.15$)$, as well as an increased risk of near fatal asthma, ${ }^{18} \mathrm{RR}=$ 2.02 (95\% CI 1.36 to 3.01 ). In these studies the increase in relative risk for theophylline is somewhat surprising in view of the choice of control population (patients with a hospital admission), since this population has a prevalence of theophylline usage of about $80 \%$ (in New Zealand) compared with $10-15 \%$ of the asthmatic population. As such, hospital admissions may represent an inappropriate control group to use when investigating potential drug related adverse events from the use of theophylline in pharmacoepidemiology studies $^{78}$ - that is, oral theophylline may increase the severity or the frequency of severe attacks so that patients with a hospital admission (controls) would be intermediate in the causal pathway. Whilst the explanation that theophylline was prescribed to patients with more severe asthma is more likely, nevertheless we raise the issue since drugs other than inhaled $\beta$ agonists have been disregarded in the recent quest to find a pharmacological reason for the increase in asthma mortality rates.

Sales of inhaled steroids, particularly higher dose inhaled steroids, have increased several fold over the last decade (fig 9) and are a further possible explanation for the reduction in asthma mortality and admission rates. Higher dose inhaled steroids were registered in New Zealand for use by "specialist physicians" only in 1985 . This would have meant that patients who were at greatest risk of further morbidity or of mortality would have been channelled into using the high dose inhaled steroids soon after their release from hospital. Perhaps as a reflection of this, readmissions for asthma began to fall substantially in 1986 (fig 5), three years before the fenoterol studies were first published. High dose inhaled steroids were made available to general practitioners subsequently in 1987 and first admissions with asthma began to fall two years later. The prescription of these drugs indicates an increasing use of "disease modifying" drugs and may also reflect heightened awareness of, and general improvements in, asthma management - that is, they may be a marker of good general care as is suggested in our study of peak flow meter usage. ${ }^{59}$ Despite the fact that inhaled steroids would have been channelled for use in the most severe subgroups of asthmatic patients and that there was relatively little use of high dose inhaled steroids at the time the Wellington research group's studies were undertaken, ${ }^{15-17}$ none of the studies showed a positive association between inhaled steroids and mortality. The Saskatchewan study ${ }^{79}$ actually suggests that higher dose inhaled steroids are 
protective of mortality or severe life threatening attacks. Clinical experience in New Zealand suggests that it has been the increased use of appropriate doses of inhaled steroid ${ }^{80}$ and associated strategies which have had the greatest impact on morbidity. Although there is a paucity of dose-response data in the literature, it is acknowledged that escalating doses of inhaled steroids lead to an improvement in asthma control and allow reduction or withdrawal of systemic steroid therapy. ${ }^{81-83}$ Increasing use of higher doses of inhaled steroids represents the biggest change in asthma drug management over the latter part of the 1980 s (figs 6 and 9), and its potential impact would be difficult to ignore. Furthermore, other countries where inhaled fenoterol was either not registered or where it has not been restricted are beginning to experience reductions in asthma mortality and admission rates as higher doses of inhaled steroids are increasingly prescribed. ${ }^{84} 85$

\section{Summary}

Increasing financial barriers to primary health care against a background of social and economic decline are likely to have contributed to asthma morbidity and mortality in New Zealand. Although there would not have been a sufficient increase in asthma prevalence to have accounted for the threefold increase in mortality rates, whether or not there was an increase in asthma severity in the late 1970s remains open to debate. Misuse or poor use of newly available and potent bronchodilator medications by those with the most severe asthma may simply have contributed to further delays in obtaining appropriate care and therefore to an increase in frequency of severe attacks in the community. Despite substantial increases in the use of bronchodilator therapy in New Zealand, there was no immediate improvement in indices of either asthma morbidity or mortality. The initial reduction in mortality rates in the $1980 \mathrm{~s}$ happened at a time when first admissions for asthma were still increasing and seems to be best explained by an improvement in utilisation of hospital services (which were free until 1992) rather than a reduction in asthma severity. However, the recent reductions in all measures of asthma morbidity and the further reduction in asthma mortality since 1989 does now suggest a reduction in asthma severity and would be best explained by the substantial increase in medium and high dose inhaled corticosteroid use, and to the endorsement of the current management strategies for asthma which are being promoted internationally ${ }^{8687}$ and which were given considerable publicity in New Zealand in 1989 and 1990. Whilst sales of inhaled $\beta$ agonists were higher in 1991 than 1989 , this may not reflect their pattern of use by individual patients since the need for an increase in inhaled $\beta$ agonist treatment has been accepted as indicating a lack of control and the need for either starting or increasing the dose of inhaled steroid treatment.
The authors would like to thank the National Health Statistics Centre and the New Zealand St Johns Ambulance Association for providing relevant information, the editors of the New Zealand Medical fournal and of the Australian and New Zealan Medical fournal for permission to publish figs 2 and $3, \mathrm{Ms}$ Josephine Ratnasabapathy and Miss Margaret McKinlay for secretarial assistance, and IMS (NZ) Limited for permission to use their national drug sales data.

1 Jackson RT, Beaglehole R, Rea HH, Sutherland DF. Mortality from asthma: a new epidemic in New Zealand. $B M F$ 1992;285:771-4.

2 Sears MR, Rea HH, Beaglehole R, Gillies AJ, Holst P, O'Donnell TV, et al. Asthma mortality in New Zealand: a two year national study. NZ Med $₹$ 1985;98:271-5.

3 Rea HH, Sears MR, Beaglehole R, Fenwick J, Jackson $\mathrm{RT}$, Gillies JD, et al. Lessons from the National Asthma Mortality Study: circumstances surrounding death. NZ Med f 1987;100:10-13.

4 Jackson R, Sears MR, Beaglehole R, Rea HH. International trends in asthma mortality: 1970 to 1985 . Chest 1988 ;94: 914-8.

5 Milne GA. The incidence of asthma in Lower Hutt. NZ Med f 1969;70:27-9.

6 Mitchell EA. Increasing prevalence of asthma in children NZ Med F 1983;96:463-4.

7 Mitchell EA. Is current treatment increasing asthma mortality and morbidity? Thorax 1989;44:81-4.

8 Garrett JE, Mulder J, Wong-Toi H. Characteristics of asthmatics using an urban accident and emergency deparment. NZ Med ₹ 1988;101:359-61.

9 Garrett JE, Mulder J, Wong-Toi H. Reasons for racial differences in $\mathrm{A} \& \mathrm{E}$ attendance rates for asthma. $\mathrm{NZ} \mathrm{Med}$ 7 1989;102:121-4

10 Garrett JE, Mulder J, Veale AG. Trends in the use of an urban accident and emergency department by asthmatics. urban accident and emergen

11 Wilson JD, Sutherland DC, Thomas AC. Has the change to beta-agonists combined with oral theophylline increased cases of fatal asthma? Lancet $1981 ; \mathrm{i}: 1235-7$.

12 Sutherland DC, Beaglehole R, Fenwick J, Jackson RT Mullins P, Rea HH. Death from asthma in Auckland: circumstances and validation of causes. NZ Med $\mathcal{f} 1984$ 97:845-8.

13 Sears MR, Rea HH. Patients at risk for dying of asthma: New Zealand experience. $\mathcal{F}$ Allergy Clin Immunol 1987;80: 477-81.

14 Rea HH, Scraggs R, Jackson R, Beaglehole R, Fenwick J Sutherland DC. A case-control study of deaths from Sutherland DC. A case-contro

15 Crane J, Pearce NE, Flatt A, Beasley R. Prescribed fenoterol and death from asthma in New Zealand, 1981-1983. Case-control study. Lancet 1989;i:917-22.

16 Pearce NE, Grainger J, Atkinson M, Crane J, Beasley R. Case-control study of prescribed fenoterol and death from asthma in New Zealand, 1977-1981. Thorax 1990;45: $170-5$.

17 Grainger J, Woodman K, Pearce NE, Crane J, Beasley $R$. Prescribed fenoterol and death from asthma in New Zealand, 1981-1987: a further case-control study. Thorax 1991;46:105-11.

18 Burgess C, Pearce N, Thiruchelvam R, Wilkinson R, Linaker $\mathrm{C}$, Woodman $\mathrm{K}$, et al. Prescribed drug therapy and nearfatal asthma attacks. Eur Respir f 1994;7:498-503.

19 Garrett JE, Kolbe J, Rea HH, Lanes S. Risk of severe life-threatening asthma (SLTA) and type of prescribed $\beta$ agonist: an example of confounding by severity. Aust NZ fMed 1994;24:433.

20 Kolbe J, Garrett JE, Rea HH, Lanes S. Beta agonist type and outcome after severe life-threatening attack of asthma Aust NZ ₹ Med 1994;24:448.

21 Sears MR, Taylor DR, Print CG, Lake DC, Li Q, Flannery $\mathrm{EM}$, et al. Regular inhaled beta agonist treatment in bronchial asthma. Lancet 1990;336:1391-6.

22 Asher MI, Pattemore PK, Harrison AC, Mitchell EA, Rea $\mathrm{HH}$, Stewart AW. International comparison of the prevalence of bronchial hyperresponsiveness and asthma symptoms. Am Rev Respir Dis 1988;138:524-9.

23 Fitzgerald JM, Sears MR, Roberts RS. Symptoms of asthma and airway hyperresponsiveness to methacholine in a population of Canadian schoolchildren. Am Rev Respir population of Can $1988 ; 137: 285$.

24 Sears MR, Jones DT, Holdaway MD. Prevalence of bronears MR, Jones DT, Holdaway MD. Prevalence of bronchial reactivity to inhaled methach
children. Thorax $1986 ; 41: 283-91$.

25 Pattemere PK, Asher MI, Harrison AC, Mitchell EA, Rea HH, Stewart AW. Ethnic differences in prevalence of $\mathrm{HH}$, Stewart AW. Ethnic differences in prevalence of asthma symptoms and bronchial hyperresponsiven

26 Pattemore PK, Asher MI, Harrison AC, Mitchell EA, Rea $\mathrm{HH}$, Stewart AH. The interrelationship among bronchial hyperresponsiveness. The diagnosis of asthma and asthma symptoms. Am Rev Respir Dis 1990;142:549-54.

27 Crane J, Lewis S, Salter T, Crossland L. Robson B, D'Souza, et al. The self reported prevalence of asthma symptoms amongst New Zealanders. NZ Med $\mathcal{F} 1995$ (in press).

28 Janson C, Bjornsson E, Gislason T, Gislason M, Iverson E, Norrman E, et al. Respiratory symptoms and the use of medication for asthma in six Nordic areas. Eur Respir 7 1993;6(Suppl 17):340s.

29 Toelle BG, Peat JK, Salome CJ, Mellis C, Woolcock AJ. Toward a definition of asthma for epidemiology. Am Rev Respir Dis 1992;146:633-7. 
30 Anderson HR, Butland BK, Strachan DP. Trends in prevalence and severity of childhood asthma. BMf 1994;308. $1600-4$.

31 Burr ML, Butland BK, King S, Vaughan-Williams E. Changes in asthma prevalence: two surveys 15 years apart. Arch Dis Child 1989;64:1452-6.

32 Peat JK, van den Berg RH, Green WF, Mellis CM, Leeder SR, Woolcock AJ. Changing prevalence of asthma in Australian children. BMF 1994;308:1591-6.

33 Anderson HR. The epidemiological value of hospital diagnostic data. In: Bennett $\mathrm{AE}$ ed. Recent advances in community medicine. Edinburgh: Churchill Livingstone, 1978: 175-94.

34 Van Schayck CP, Van Herwaarden C. Do bronchodilators affect the prognosis of bronchial hyperresponsiveness? Thorax 1993;48:470-3.

35 Brosnan PA. Unemployment and the invalid's benefit. NZ Population Review 1987;13:1:71-9.

36 Miles JF, Garden GM, Tunnicliffe W, Cayton M, Ayres JG.Physiologic morbidity and coping skills in patients with brittle and non-brittle asthma: a case-control study. Thorax 1994;49:1044P.

37 Jackson GP. Asthma mortality by neighbourhood of domicile. NZ Med f 1988;101:593-5.

38 Richards GN, Kolbe J, Fenwick J, Rea HH. Demographic characteristics of patients with severe life-threatening asthma: comparison with asthma deaths. Thorax 1993;48: 1105-9.

39 Roberts I. Controlling for socioeconomic disadvantage in epidemiologic analyses. NZ Med f 1994;107:350-1.

40 Beasley R, Pearce NE, Crane J, Windon I, Burgess L. Asthma mortality and inhaled beta agonist therapy. Aust NZ ₹ Med 1991;21:753-8.

41 Keating G, Mitchell EA, Jackson R, Rea HH. Trends in sales of drugs for asthma in New Zealand, Australia and sales of drugs for asthma in New Zealand, Australia and

42 Jackson RT, Mitchell EA. Trends in hospital admission rates and drug treatment of asthma in New Zealand. NZ Med f 1983;96:727-9.

43 Esdaile JM, Feinstein AR. Horwitz RI. A reappraisal of the United Kingdom epidemic of fatal asthma. Can general mortality data implicate a therapeutic agent? Arch Intern Med 1987;147:543-9.

44 Rea HH, McNaughton S, Smith LT, Mitchell EA, Asher I. Asthma morbidity: the influence of patient and family knowledge and self-management behaviour. Am Rev Respir Dis 1990;141:A494.

45 Rea HH, Garrett JE, Mulder J, Rebuck A, White, Chapman $\mathrm{K}$. Emergency room care of asthmatics: a comparison between Auckland and Toronto. Ann Allergy 1991;66: 48-52.

46 Report of the Beta Agonist Working Party. Committee on Safety of Medicines, United Kingdom, January 1992. Cur Probl 1992;32:1-2.

47 Spitzer WO, Suissa S, Ernst P, Horwitz P, Habbick B, Lockcroft $D$, et al. The use of $\beta$ agonist and risk of death and near death from asthma. $N$ Engl $f$ Med 1992;326: and near

48 Suissa S, Ernst P, Boivin JF, Horwitz RI, Habbick B Cockroft $\mathrm{D}$, et al. A cohort analysis of excess mortality in asthma and the use of $\beta$ agonists. Am $\mathcal{f}$ Respir Care Med 1994;149:604-10.

49 Windom HH, Burgess CD, Crane J, Pearce N, Beasley $R$. The self-administration of inhaled beta agonist drug during severe asthma. NZ Med f 1990;103:205-7.

50 Hodgkin JE. United States audit of asthma therapy. Chest 1986;90(Suppl 5):621-626.

51 Vermiere PA, Wittesacle WM, Jaussens E. European audit of asthma therapy. Chest 1986;90(Suppl 5):58-61.

52 Mitchell EA, Anderson HR, Freeling R, White PJ. Why are hospital admissions and mortality rates for childhood asthma higher in New Zealand than in the United Kingdom? Thorax 1990;45:176-82.

53 Epton MJ, O'Hagan J, Curry C, Wood-Baker R, Town GI. An audit and international comparison of asthm management in the emergency department. NZ Med $\mathscr{F}$ 1994;107:26-9.

54 Reed S, Diggle S, Cushley MJ, Sleet RA, Tattersfield AE. Assessment and management of acute asthma in an accident and emergency department. Thorax 1985;40:897902 .

55 Epden P, Karey OJ, Quinton D, Cookson JB. A study of acute asthma in the accident and emergency department. $\operatorname{Br} \mathcal{F}$ Dis Chest 1988;82:162-7.

56 Sears MR, Rea HH, Rothwell P. Asthma mortality: comparison between New Zealand and England. BMF 1986; 293:1342-5.

57 Hodges ID, Wilkie A, Drennan C, Town GI. A community wide promotion of asthma self management - process evaluation. NZ Med f 1993;106:354-6.
58 Town GI, Epton MJ, Rigby S, Garrett J, Crane J, Armstrong $\mathrm{R}$, et al. Self-management skills and the impact of economic factors in patients with asthma. Proceedings TSANZ Annual Scientific Meeting 1993.

59 Garrett JE, Mercer J, Fenwick J, Taylor G, Mitchell E, Rea HH. Peak expiratory flow meters (PEFMs) - who uses them and how and does education affect the pattern of utilisation? Aust NZ Med f 1994;24:521-9.

60 Kolbe J, Every S, O'Hagan A, Richards G, Garrett J, Rea $\mathrm{HH}$. Outcome following a severe life-threatening attack (SLTA) of asthma: influence of asthma clinic. Aust NZ Med 1990;203:515A.

61 McClellan VE, Garrett JE. Attendance failure at Middlemore Hospital asthma clinic. NZ Med $\mathcal{f} 1989,102: 211-3$.

62 Strachan DP, Anderson HR. Trends in hospital admission rates for asthma in children. $B M \mathcal{F}$ 1992;304:819-20.

63 Hallam L. Primary medical care outside normal working hours: review of published work. BMF 1994;308:249-52.

64 New Zealand Department of Health Special Report Serie No. 70. Accident and Emergency Organisation and Utilisation, 1984.

65 Mitchell EA. International trends in hospital admission rates for asthma. Arch Dis Child 1985;60:376-8.

66 Crane J, Pearce N, Burgess C, Beasley R. Asthma deaths in New Zealand. $B M \mathcal{F}$ 1992;304:1307.

67 Petri $\mathrm{H}$, Urquhart J, Herings $R$, Bakker A. Characteristics of patients prescribed three different inhalational beta-2 agonists: an example of the chanelling phenomenon. PostMarketing Surveillance 1991;3:57-66.

68 Garrett JE, Turner $P$. The severity of asthma in relationship to $\beta$ agonist prescribing. NZ Med $\mathcal{f} 1991 ; 104: 39-40$.

69 Van Schayck CP, Dompeling E, Van Herwaarden CLA, Folgering H, Verbeek ALM, van der Hoogan HJM, et al. Bronchodilator treatment in moderate asthma or chronic bronchitis: continuous or on demand? A randomised controlled study. BMF 1991;303:1426-31.

70 Kraan J, Koeter GH, Van Der Mark Th W, Sluiter HJ, de Vries K. Changes in bronchial hyperreactivity induced by four weeks of treatment with anti-asthmatic drugs in patients with allergic asthma: a comparison between budesonide and terbutaline. $\mathcal{F}$ Allergy Clin Immunol 1985;76: 628-36.

71 Peel ET, Gibson GJ. Effects of long term inhaled salbutamol therapy on the provocation of asthma by histamine. Am Rev Respir Dis 1980;121:973-87.

72 Patakas D, Maniki E, Tsura V. Intermittent and continuous salbutamol rotacaps inhalation in asthmatic patients. Respiration 1988;54:174-8.

73 Shepherd GL, Hetzel MR, Clark TJH. Regular versus symptomatic aerosol bronchodilator treatment of asthma. $\mathrm{Br} \mathcal{F}$ Dis Chest 1981;75:215-7.

74 Lanes S. Matching or selection bias in the fenoterol studies? NZ Med f 1992;105:413.

75 Garrett JE, Kolbe J, Richards GN, Whitlock RML, Rea $\mathrm{HH}$. Asthma in New Zealand: trends in drug treatment, hospital admissions and mortality rates, 1981-1991. Am Rev Respir Dis 1993;147:A798.

76 Garrett J. Asthma deaths in New Zealand. BMF 1992;305: 889.

77 Suissa S, Enst P, Spitzer WO. Asthma deaths in New Zealand. BMF 1992;305:889.

78 Miettinon OS. Theoretical epidemiology. New York: John Wiley and Sons, 1985:69.

79 Ernst P, Spitzer WO, Suissa S, Cockcroft D, Habbick B, Horwitz RI, et al. Risk of fatal and near fatal asthma in relation to inhaled corticosteroid use. $\mathcal{F A M A} 1992 ; 268$ : 3462-4.

80 Karalus N, Harrison AC. Inhaled high-dose beclomethasone in chronic asthma. NZ Med $\mathcal{7} 1987 ; 100: 305-8$.

81 Brompton Hospital and Medical Research Council. Doubleblind trial comparing two dosage schedules of beclomethasone diproprionate aerosol with a placebo in chronic bronchial asthma. Br f Dis Chest 1979;73:121-32.

82 Toogood JH, Lefcoe NM, Haines DSMA. A graded dose assessment of the efficacy of beclomethasone diproprionate aerosol for severe chronic asthma. 7 Allergy Clin Immunol 1977;59:298-305.

83 Smith MJ, Hudson ME. High dose beclomethasone inhaler in the treatment of asthma. Lancet 1983;i:265-8.

84 Gerdtham UG, Hertzman P, Boman G, Johnsson B. Impact of inhaled corticosteroids in asthma hospitalisation in Sweden: a pooled regression analysis. EFI Research Report, 1993

85 Hertzman P. Hospital and social costs of acute asthma. Res Clin Forums 1993;15(4 pt 1):23-31.

86 Thoracic Society of Australia and New Zealand (TSANZ) Consensus on asthma: asthma management plan 1989. NZ Med F 1990;103:16-8.

87 British Thoracic Society. Guidelines for management of asthma. Thorax 1993;48:S1-24. 